\title{
Urgences
}

\section{c'est la phrase...}

\section{Vianney Gallant}

Numéro 13, mars 1986

\section{Éclats d'atelier}

URI : https://id.erudit.org/iderudit/025229ar

DOI : https://doi.org/10.7202/025229ar

Aller au sommaire du numéro

\section{Éditeur(s)}

Urgences

\section{ISSN}

0226-9554 (imprimé)

1927-3924 (numérique)

Découvrir la revue

\section{Citer ce document}

Gallant, V. (1986). c'est la phrase... Urgences, (13), 65-66. https://doi.org/10.7202/025229ar

Ce document est protégé par la loi sur le droit d'auteur. L'utilisation des services d'Érudit (y compris la reproduction) est assujettie à sa politique d'utilisation que vous pouvez consulter en ligne.

https://apropos.erudit.org/fr/usagers/politique-dutilisation/ 


\section{Vianney Gallant}

c'est la phrase sujet verbe complément le jeu voit des chandelles virgulisées qui disent que les trucs d'écriture sont à la littérature ce que les gadgets de sex-shop sont à l'amour peut-être la phrase pour être moins compréhensible donc lucide et comparaître devant l'ordinatexte piédestalisant mon analité dans quelque narrème ou pour un grand éclat de rire de mes petites lèvres viriles guili guili torvis à testicules sémiotiques aimer dans le creux de l'oreille sodomisante celle qui vient comme une petite frappe

poète de bords salon via poétesse à talons ronds petite frappe automatique sans autocritique qui garrocherait le mépris à coups de je thème de sèmes de phonèmes de masturbations narratives et de narratologie coïtale jusqu'a la feuille qui tombe mirage mi-joie d'automne s'ouvre animiste un silence bleu ou noir de plomb d'esthétique mnémonique

j'agraphe des instants phoniques modulaires allégorisant en dehors de la saloperie des grimages phosphorescents et du lobbying inconsciemment nymphormatique j'émissionne en transe minute bonhomme les palimpsestes d'une exégèse du corps sexshoppisée ou sur la syntaxe avec laquelle tu vas la prendre si je ne réussis pas en toutes lettres à te la performer ma rage et la distance qui nous sépare et le vide que de toute façon elle engendre et d'où elle vient aussi plausible que de te crier ma meurtrissure et qui me donne le droit inaliénable de parler au je craché mouché torché masqué multiplié divisé synthétisé n'importe où n'importe comment avec n'importe qui jusqu'à ce que j'en crève virgule sujet verbe complément je m'en fous éperdument je chavire le sonore et le visuel je te sème tu me funaimes il signifiose tu récoltes sur l'oeil de toute façon l'agonie de cette insignifiance qui m'enclot les rêves entre deux rages jusqu'à m'éteindre complètement parce que je n'ai rien à pornographier sujet verbe complément l'un après l'autre sans nommer personne au nom de l'idéologie éreintée par le masque et du texte que je ne terminerai jamais

j'aimais pour- 
tant que tu lises écrives jusque dans mes moindres gestes les quelques petites allusions au bonheur ou à la sérénité possible je te dactylographie d'après le brouillon ces lignes de la main à l'âme parce que te voir m'enivre jusqu'à l'os graphème actantialisé et tous les etcétératés du monde qui font croire au contraire pour qu'une seule fois tu me laisses dire je à la poubellication des miroirs elle vient de je ne sais où et pour cause car sur le corps je te le tapais mon amour totem ce texte fétiche toi sujet verbe complément maintenant seulement le graphisme après le brouillon de l'âme m'encule ce rêve d'auditoire déstructuré la plus courte distance entre deux inventions c'est toi mon amour de lettres exorcisées

la dernière fois que j'eus recours à toi pour me soulager de mes angoisses de grande noirceur phonique tu m'as signifié de placer sur la feuille le plus de sang possible entre deux arbres à parenthèses et je te le fais cet oeil au beurre noir à la page du silence ad libitum de tes peurs pour que tu trouves enfin un coupable et te soulager de tes idéologies masquées et de tes sévices corporels reçus par d'autres moi je n'en peux plus justement de naître et de vêler les images de toutes ces catastrophes cacaphoniquement élues ou tues je n'en peux plus d'aigrire à perte de vue la glaire de tous mes noeuds gestuels et de tous mes cris de vos entrailles-est-béni voilà pour le mot à mot de l'âme sujet verbe complément qui est sujet qui est verbe qui est complément voilà tout le problème de cette fameuse distance qui m'empêche de te sémantiser en idiotvirtuel toute la force de mon désespoir entre deux points j'aurais pu décomposer jusqu'au vide structurel ta chair et te la confier fielleusement avec le sourire des habitués à la folie doucement retenue et méritocratisée mais je te la crie désespérément cette distance leitmotivée parce qu'elle ne réussit jamais à se combler d'elle-même sujet verbe complément ad libitum pour que meurre le blanc seulement sur le papier parce que le silence est trop aigu dissident trop strident sujet verbe complément qui ne révolutionne jamais rien d'autre que sa propre folie de détruire de remplir cette maudite blanche agonie de retenir l'envie de te les baver entre deux colères ces fameux yeux au beurre noir du sens et de la structure pour que tu aies l'air de ce que tu es et de ce que tu seras toujours autant que moi un grand trou de cul idéalisé j'ai dépassé les bornes ma chère euphonie de lettres et de non-sens ad libidinum sujet verbe complément en un seul prétexte cette fameuse distance entre deux points vingt-trois heures trente une colère ou une phrase mais 